\title{
Diagnostic utility of monitoring cytomegalovirus-specific immunity by QuantiFERON-cytomegalovirus assay in kidney transplant recipients
}

Dominika Deborska-Materkowska", Agnieszka Perkowska-Ptasinska', Anna Sadowska', Jolanta Gozdowska', Michał Ciszek ${ }^{2}$, Marta Serwanska-Swietek ${ }^{3}$, Piotr Domagala ${ }^{3}$, Dorota Miszewska-Szyszkowska ${ }^{1}$, Elzbieta Sitarek', Agnieszka Jozwik ${ }^{3}$, Artur Kwiatkowski ${ }^{3}$ and Magdalena Durlik ${ }^{1}$

\begin{abstract}
Background: Despite universal prophylaxis, late cytomegalovirus (CMV) infection occurs in a high proportion of kidney transplant recipients. We evaluated whether a specific viral T-cell response allows for the better identification of recipients who are at high risk of CMV infection after prophylaxis withdrawal.

Methods: We conducted a prospective study in 19 pretransplant anti-CMV seronegative kidney graft recipients R- (18 from seropositive donors [D+] and one from a seronegative donor [D-]) and 67 seropositive recipients $R(+)$ (59 from seropositive donors and eight from seronegative donors) who received antiviral prophylaxis with valganciclovir. The QuantiFERON-CMV (QF-CMV) assay was performed within the first and third months after transplantation. Blood samples were monitored for CMV DNAemia using a commercial quantitative nucleic acid amplification test (QNAT) that was calibrated to the World Health Organization International Standard.
\end{abstract}

Results: Twenty-one of the 86 patients (24\%) developed CMV viremia after prophylaxis withdrawal within 12 months posttransplantation. In the CMV R(+) group, the QF-CMV assay yielded reactive results (QF-CMV[+]) in 51 of 67 patients (76\%) compared with 7 of 19 patients (37\%) in the CMV R(-) group ( $p=0.001)$. In the CMV R(+) group, infection occurred in seven of 16 recipients (44\%) who were QF-CMV(-) and eight of 51 recipients (16\%) who were QF-CMV $(+)$. In the CMV R(-) group, infection evolved in five of 12 recipients (42\%) who were QF-CMV $(-)$ and one of 7 recipients (14\%) who were QF-CMV(+). No difference was found in the incidence of CMV infection stratified according to the QF-CMV results with regard to the recipients' pretransplant CMV IgG serology ( $p=0.985)$. Cytomegalovirus infection occurred in 15 of 36 patients (42\%) with hypogammaglobulinemia (HGG) 90 days posttransplantation compared with two of 34 patients $(6 \%)$ without HGG $(p=0.0004)$. Cytomegalovirus infection occurred in seven of 13 patients (54\%) with lymphocytopenia compared with 14 of 70 patients (20\%) without lymphocytopenia $(p=0.015)$. The multivariate analysis revealed that the nonreactive QuantiFERON-CMV assay was an independent risk factor for postprophylaxis CMV infection.

(Continued on next page)

\footnotetext{
* Correspondence: dominika.deborska@wp.pl

${ }^{1}$ Department of Transplantation Medicine, Nephrology, Internal Diseases, T.

Orłowski Institute of Transplantation Medical University of Warsaw, 59

Nowogrodzka Street, 02-006 Warsaw, Poland

Full list of author information is available at the end of the article
}

(c) The Author(s). 2018 Open Access This article is distributed under the terms of the Creative Commons Attribution 4.0 International License (http://creativecommons.org/licenses/by/4.0/), which permits unrestricted use, distribution, and reproduction in any medium, provided you give appropriate credit to the original author(s) and the source, provide a link to the Creative Commons license, and indicate if changes were made. The Creative Commons Public Domain Dedication waiver (http://creativecommons.org/publicdomain/zero/1.0/) applies to the data made available in this article, unless otherwise stated. 
(Continued from previous page)

Conclusions: In kidney transplant recipients who received posttransplantation prophylaxis, negative QF-CMV results better defined the risk of CMV infection than initial CMV IgG status after prophylaxis withdrawal. Hypogammaglobulinemia and lymphocytopenia were risk factors for CMV infection.

Keywords: Kidney transplantation, QuantiFERON-cytomegalovirus, Postprophylaxis, Cytomegalovirus infection, Hypogammaglobulinemia, Valganciclovir,

\section{Background}

Despite remarkable advances in the diagnostic and therapeutic modalities for its management, cytomegalovirus (CMV) remains a significant cause of serious infectious complications and occasionally mortality in immunocompromised patients [1]. Solid organ transplant recipients are at high risk for CMV infection, especially during the first 3-12 months after transplantation, because of high initial immunosuppression. Two main strategies are used to prevent CMV infection: prophylaxis of viral infections using antiviral drugs and preemptive therapy for organ recipients who develop evidence of CMV infection during routine screening [24]. Both strategies have resulted in significant reductions of CMV infection and CMV-related mortality. Prophylaxis usually begins shortly after transplantation and continues for a finite period of time, often in the range of 3-6 months. However, such a strategy has not led to the elimination of postprophylaxis CMV infection. Moreover, this strategy has led to a higher risk of developing anti-CMV drug resistance, a higher cost of antiviral medications, and a greater risk of side effects, with many patients who are overtreated $[5,6]$.

The highest risk of CMV disease involves $15-25 \%$ of organ transplant recipients who are seronegative for CMV (R-) and receive organs from seropositive donors (D+) [7]. Thus, the management of CMV infection in kidney graft recipients has been driven by donor and recipient pretransplant serology $[8,9]$. However, the incidence of CMV infection is significant not only in high-risk recipients $(\mathrm{D}+/ \mathrm{R}-)$ but also in lower-risk recipients $(\mathrm{D}-/ \mathrm{R}+, \mathrm{D}+/ \mathrm{R}+)[4,10-$ 12]. Moreover, some high-risk patients never develop CMV infection despite not receiving any prophylaxis treatment $[2,13]$. These observations suggest that both the presence of CMV-specific IgG antibodies and prolonged immune system activation contribute to the development of CMV infection after transplantation.

We evaluated whether a specific viral T-cell response allows for the better identification of recipients who are at high risk of CMV infection after prophylaxis withdrawal.

\section{Methods}

\section{Study design and participants}

We conducted a prospective follow-up study of kidney graft transplant recipients in the Department of General and Transplant Surgery, T. Orłowski Institute. A total of 103 consecutive adult kidney transplant recipients were initially enrolled in the study between April and November 2014. To make the study population more homogeneous, we excluded 17 recipients from the analysis (Fig. 1).

The remaining 86 kidney transplant recipients were enrolled in the study and were followed for 360 days posttransplantation. According to the institutional protocol, all but one patient (D-/R-) received antiviral prophylaxis with valganciclovir, with the dose adjusted to kidney graft function. CMV prophylaxis was given for 3 months in all but five patients. CMV prophylaxis was stopped before the end of the third month in these recipients because of severe leucopenia that did not respond to mycophenolate mofetil dose reduction and/or GM-CSF treatment.

Immunosuppression was performed according to the institutional protocol. A total of $80.2 \%$ of the recipients received induction therapy, and $98.0 \%$ received triple maintenance therapy with a combination of prednisone, tacrolimus, and antimetabolite (mycophenolate mofetil or mycophenolate sodium; Table 1).

The primary endpoint of the study was the incidence of CMV infection within 360 days posttransplantation. We hypothesized that the CMV-specific T-cell assay that was performed early posttransplantation may allow for the better identification of recipients who are at risk of postprophylaxis CMV infection. The secondary objective was the analysis of other potential risk factors for postprophylaxis CMV infection. Based on the criteria recommended by the American Society of Transplantation for use in clinical trials, the following definitions applied:

- CMV infection: CMV DNAemia regardless of symptoms.

- CMV disease: evidence of CMV infection with attributable symptoms.

- CMV DNAemia without symptoms: detection of CMV DNA in plasma [8].

\section{Procedures}

Cytomegalovirus DNA quantification was performed using plasma samples on days 30,90 , and 360 postkidney transplantation and additionally at the discretion of the treating physician. Cytomegalovirus DNAemia 


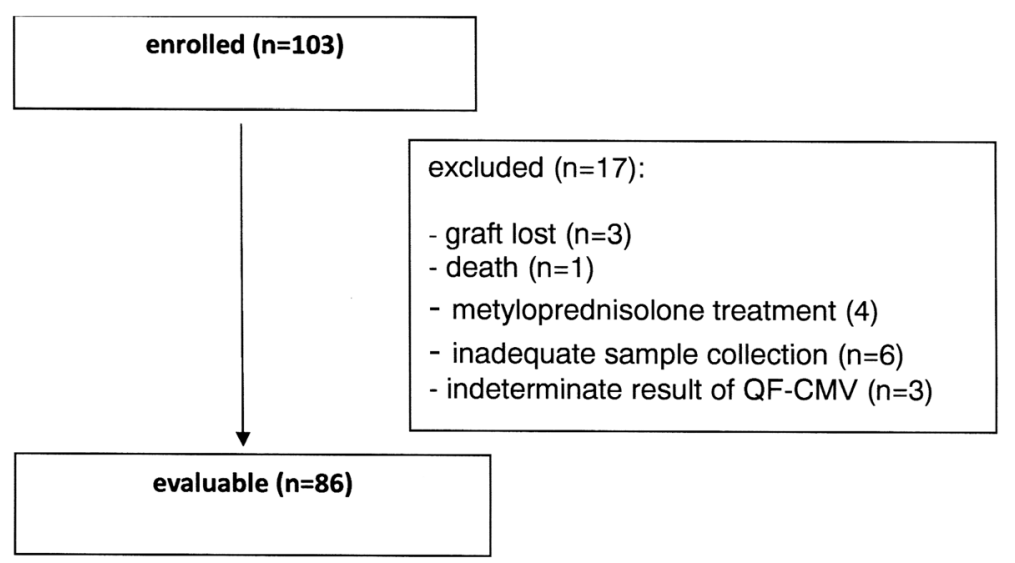

Fig. 1 Baseline characteristics of the study participants

was evaluated in plasma using a commercial quantitative nucleic acid amplification test (SmartCycler II, Cepheid AB, Sunnyvale, CA, USA) that was calibrated to the 1st World Health Organization International Standard. The limit of detection was $50 \mathrm{copies} / \mathrm{ml}$, with linearity of 500-107 copies/ml. The CMV-specific T-cell response was evaluated at three time points: 7, 30, and 90 days posttransplantation.

QuantiFERON-CMV analysis QuantiFERON-CMV is an enzyme-linked immunosorbent assay-based interferon$\gamma($ IFN- $\gamma$ ) release CD8+ assay that has been accepted and commercialized by the European Union. The assay was performed according to the manufacturer's instructions. Peripheral blood was collected in three $(3 \times 1 \mathrm{ml})$ heparinized tubes. Tube 1 contained a mixture of human cytomegalovirus peptide epitopes. Tube 2 contained phytohemagglutinin (positive control). Tube 3 contained sterile phosphate-buffered saline (negative control). After blood collection by venipuncture, the tubes were gently shaken (10 times up and down) and then incubated overnight for $18-24 \mathrm{~h}$ at $37^{\circ} \mathrm{C}$. All of the tubes were then centrifuged for $15 \mathrm{~min}$ at 2500 relative centrifugal force, and plasma was collected and stored at $-80^{\circ} \mathrm{C}$. Specific IFN- $\gamma$ levels were measured using a standard enzyme-linked immunosorbent assay. According to the manufacturer, the results were considered positive when the peptide response was $\geq 0.2 \mathrm{IU} / \mathrm{ml}$ of IFN- $\gamma$. If the level of IFN- $\gamma$ in the CMV antigen tube was $<0.1 \mathrm{IU} / \mathrm{mL}$ and in the mitogen tube was $<0.5 \mathrm{IU} / \mathrm{mL}$, then the result was considered indeterminate [14].

Detection of CMV-specific antibodies Specific serum anti-CMV IgG titer was measured with the ARCHITECT CMV IgG assay (Abbott Laboratories, Dublin, Ireland) according to the manufacturer's instructions. The ARCHITECT CMV IgG assay is a chemiluminescent microparticle immunoassay that is designed to have a precision of $\leq 10 \%$ total (total is an accumulation of within run, between run and between day) $\mathrm{CV}$ (coefficient of variation) for representative specimens within the ranges of 6-60 $\mathrm{AU} / \mathrm{ml}$ and 200-250 AU/ml. Among transplant recipients, relative sensitivity is $100 \%$ (lower $95 \%$ confidence limit of $91.96 \%$ ) and specificity is $100 \%$ (lower $95 \%$ confidence limit of $93.62 \%$; from the manufacturer's information brochure). Other commercial tests were performed according to the manufacturer's instructions.

Hypogammaglobulinemia (HGG) was defined as a total gamma globulin blood concentration $<0.8 \mathrm{~g} / \mathrm{dl}$, determined by capillary electrophoresis. Gammaglobulin blood concentration was examined on day 0 (before transplantation) and on day 90 post-kidney transplantation. Lymphocytopenia was defined as a lymphocyte blood count $<0.8 \mathrm{G} / \mathrm{L}$, determined by fluorescence flow cytometry. Lymphocyte blood count was evaluated at three time points: 0,30 , and 90 days posttransplantation. The estimated glomerular filtration rate was calculated by the abbreviated Modification of Diet in Renal Disease equation.

\section{Ethics}

The study was approved by the Ethical Committee of Medical University of Warsaw and complied with the provisions of the Good Clinical Practice Guidelines and the Declaration of Helsinki. All patients provided written informed consent prior to participation.

\section{Statistical analyses}

Qualitative variables were compared using the $x^{2}$ statistic that follows the $\chi^{2}$ distribution ( $\chi^{2}$ test) or hypergeometric distribution (Fisher's exact test), depending on the sample size (i.e., $X^{2}$ test when the expected values are $>5$ and Fisher's exact test otherwise). The Mantel-Haenszel test was used to analyze the odds for stratified sampled data. The test is 
Table 1 Baseline characteristics of the study patients

\begin{tabular}{|c|c|}
\hline \multicolumn{2}{|l|}{ Characteristics } \\
\hline Age of recipient, years & Median: 46.5 (range: $20-74)$ \\
\hline Gender (male) N (\%) & $57(66 \%)$ \\
\hline \multicolumn{2}{|l|}{ Type of transplant N (\%) } \\
\hline Kidney & $82(95.4 \%)$ \\
\hline Kidney + pancreas & $4(4.6 \%)$ \\
\hline \multicolumn{2}{|l|}{ Type of donor N (\%) } \\
\hline Living & $8(9.3 \%)$ \\
\hline Deceased & $78(90.7 \%)$ \\
\hline \multicolumn{2}{|l|}{$\begin{array}{l}\text { Pretransplant donor (D)/recipient } \\
\text { (R) CMV serostatus N (\%) }\end{array}$} \\
\hline$D+/ R-$ & $18(20.9 \%)$ \\
\hline$D-/ R-$ & $1(1.1 \%)$ \\
\hline $\mathrm{D}-/ \mathrm{R}+$ & $8(9.4 \%)$ \\
\hline $\mathrm{D}+/ \mathrm{R}+$ & $59(68.6 \%)$ \\
\hline \multicolumn{2}{|l|}{ Induction therapy N (\%) } \\
\hline Thymoglobulin & $7(8.1 \%)$ \\
\hline Basiliximab & $62(72.1 \%)$ \\
\hline None & $17(19.8 \%)$ \\
\hline \multicolumn{2}{|l|}{$\begin{array}{l}\text { Maintenance } \\
\text { immunosuppression N (\%) }\end{array}$} \\
\hline $\begin{array}{l}\text { Tacrolimus +mycophenolate } \\
\text { mofetil + prednisone }\end{array}$ & 77 (89.5\%) \\
\hline $\begin{array}{l}\text { Tacrolimus + mycophenolate } \\
\text { sodium + prednisone }\end{array}$ & $7(8.1 \%)$ \\
\hline $\begin{array}{l}\text { Cyclosprine A + mycophenolate } \\
\text { mofetil + prednisone }\end{array}$ & $1(1.2 \%)$ \\
\hline $\begin{array}{l}\text { Tacrolimus + everolimus } \\
+ \text { prednisone }\end{array}$ & $1(1.2 \%)$ \\
\hline $\begin{array}{l}\text { The time of VGCV initiation } \\
\text { (days), mean } \pm \text { SD [range] }\end{array}$ & $9 \pm 4.7[0-25]$ \\
\hline $\begin{array}{l}\text { The time of VGCV discontinuation } \\
\text { (days), mean } \pm \text { SD [range] }\end{array}$ & $92.4 \pm 13.1[53-122]$ \\
\hline $\begin{array}{l}\text { Duration of antiviral prophylaxis } \\
\text { (days), mean } \pm \text { SD [range] }\end{array}$ & $83.1 \pm 13.4$ [40-113] \\
\hline \multicolumn{2}{|l|}{$\begin{array}{l}\text { Tacrolimus concentration } \\
(\mathrm{ng} / \mathrm{mL}), \\
\text { mean } \pm \text { SD [range] }\end{array}$} \\
\hline Day 30 & $10.4 \pm 3.7[0.3-23]$ \\
\hline Day 90 & $9.5 \pm 4.5[0.3-25.2]$ \\
\hline Day 360 & $7.4 \pm 2.8[3.2-22.4]$ \\
\hline \multicolumn{2}{|l|}{$\begin{array}{l}\text { Allograft function (eGFR; } \\
\mathrm{mL} / \mathrm{min} / 1.73 \mathrm{~m} 2 \text { ), mean } \pm \mathrm{SD} \text { [range] }\end{array}$} \\
\hline Day 30 & $48.7 \pm 21.9[6.7-103.7]$ \\
\hline Day 90 & $50.4 \pm 21.0[8.5-98.9]$ \\
\hline Day 360 & $51.3 \pm 20.4[10.2-96.7]$ \\
\hline
\end{tabular}

based on summary measures of associations and provides a weighted average of the odds ratio (OR). Quantitative variables were summarized as medians (ranges) because the parameters did not follow a normal distribution and were compared using the Wilcoxon rank-sum test. Multidimensional analysis was performed using generalized logistic regression models (GLMs). To assess the goodness-of-fit and select the optimal model, the Akaike information criterion was used. Values of $p<0$. 05 were considered statistically significant. The data were analyzed using the SAS 13.2 software.

\section{Results}

\section{Patient characteristics}

The pretransplant $\mathrm{D} / \mathrm{R}$ serostatus and baseline characteristics of the recipients are summarized in Table 1.

\section{Postprophylaxis CMV infection}

No episode of CMV infection was observed while the patients were on antiviral prophylaxis. Twenty-one of 86 patients developed postprophylaxis CMV infection within 12 months posttransplantation (Table 2).

Cytomegalovirus infection occurred at a median of 48 days after the discontinuation of antiviral prophylaxis. Among the 18 patients with CMV disease, defined as evidence of CMV infection with attributable symptoms, the QuantiFERON-CMV analysis yielded positive results in 10 recipients $(56 \%)$. All of the patients with DNAemia without clinically symptomatic CMV disease had negative QuantiFERON-CMV. The proportions of CMV infection by covariate are shown in Table 3 .

\section{Risk factors of postprophylaxis CMV infection}

Serology and QuantiFERON-CMV analysis - relationship with postprophylaxis $\mathbf{C M V}$ infection The QuantiFERON-CMV assay was performed at all three time-points in 71 patients (83\%) and at two time-points

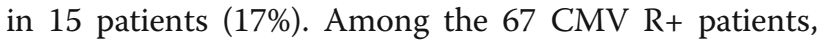
the QuantiFERON-CMV analysis yielded positive results

Table 2 Incidence of CMV infection according to donor (D) and recipient $(R)$ pretransplant serostatus

\begin{tabular}{|c|c|c|c|}
\hline \multirow[t]{2}{*}{$\mathrm{D} / \mathrm{R}(\mathrm{N})$} & \multirow[t]{2}{*}{ No CMV infection (N) } & \multicolumn{2}{|l|}{ CMV infection } \\
\hline & & $\begin{array}{l}\text { CMV DNAemia without } \\
\text { symptoms (N) }\end{array}$ & $\begin{array}{l}\text { CMV } \\
\text { disease }(\mathrm{N})\end{array}$ \\
\hline $\begin{array}{l}\mathrm{D}+/ \mathrm{R}- \\
18\end{array}$ & 12 & 1 & 5 \\
\hline $\begin{array}{l}D+/ R+ \\
59\end{array}$ & 47 & 2 & 10 \\
\hline $\begin{array}{l}\mathrm{D}-/ \mathrm{R}+ \\
8\end{array}$ & 5 & 0 & 3 \\
\hline $\begin{array}{l}\mathrm{D}-/ \mathrm{R}- \\
1\end{array}$ & 1 & 0 & 0 \\
\hline
\end{tabular}


Table 3 Relationship between selected parameters and occurrence of posttransplant CMV infection

\begin{tabular}{|c|c|c|c|}
\hline \multirow[t]{2}{*}{ Characteristics } & \multirow{2}{*}{$\begin{array}{l}\text { CMV infection } \\
N=21\end{array}$} & \multirow{2}{*}{$\begin{array}{l}\text { No CMV infection } \\
N=65\end{array}$} & \multirow[t]{2}{*}{$\mathrm{p}$} \\
\hline & & & \\
\hline Age, mean $\pm S D, y$ & $51.4 \pm 13.8$ & $46.8 \pm 15.6$ & 0.244 \\
\hline Gender, male (\%) & 57.1 & 69.2 & 0.308 \\
\hline Type of transplant, Kidney /Kidney + pancreas (\%) & $24.4 / 25.0$ & $75.6 / 75.0$ & 0.977 \\
\hline \multicolumn{4}{|l|}{ Allograft function, (eGFR), mean \pm SD } \\
\hline Day 30 & $44.0 \pm 15.4$ & $50.2 \pm 23.3$ & 0.347 \\
\hline Day 90 & $43.7 \pm 17.4$ & $52.6 \pm 21.8$ & 0.136 \\
\hline Blood transfusion, $N$ Yes/No & $12 / 9$ & $24 / 38$ & 0.140 \\
\hline Donor, D+/D- (\%) & $23.4 / 33.3$ & $76.6 / 66.7$ & 0.682 \\
\hline Pretransplant recipient CMV serostatus R+/R- (\%) & $22.4 / 33.1$ & $77.6 / 66.9$ & 0.410 \\
\hline The time of VGCV initiation after KTx (days); mean \pm SD & $9 \pm 5$ & $9 \pm 5$ & 0.905 \\
\hline The time of VGCV discontinuation after KTx (days); mean \pm SD & $94 \pm 9$ & $92 \pm 14$ & 0.458 \\
\hline Duration of antiviral prophylaxis (days); mean \pm SD & $85 \pm 9$ & $82 \pm 15$ & 0.382 \\
\hline \multicolumn{4}{|l|}{ total IgG concentration $(\mathrm{g} / \mathrm{L})<7 / \geq 7 \%$} \\
\hline Day 0 & $0.0 / 26.3$ & 100.0/73.7 & 0.571 \\
\hline Day 90 & $41.1 / 18.0$ & $58.9 / 82.0$ & 0.057 \\
\hline \multicolumn{4}{|l|}{ anti-CMV IgG titer (AU/ml) mean \pm SD } \\
\hline Day 0 & $138 \pm 113$ & $168 \pm 109$ & 0.803 \\
\hline Day 90 & $113 \pm 85$ & $159 \pm 109$ & 0.087 \\
\hline \multicolumn{4}{|l|}{ leukocyte blood count $(G / L)$ mean $\pm S D$} \\
\hline Day 0 & $7.8 \pm 2.4$ & $7.9 \pm 2.3$ & 1.000 \\
\hline Day 30 & $8.5 \pm 2.7$ & $9.2 \pm 4.0$ & 0.800 \\
\hline Day 90 & $6.6 \pm 4.9$ & $6.5 \pm 3.2$ & 0.080 \\
\hline Induction therapy (\%) & & & 0.026 \\
\hline Yes basiliximab & 25.8 & 74.2 & \\
\hline Yes thymoglobulin & 57.1 & 42.9 & \\
\hline None & 5.9 & 94.1 & \\
\hline \multicolumn{4}{|l|}{ QuantiFERON-CMV assay $(\mathrm{IU} / \mathrm{mL})<0.2 / \geq 0.2(\%)$} \\
\hline All time points used & $42.9 / 15.6$ & $57.1 / 84.4$ & 0.005 \\
\hline Day 7 & $39.0 / 14.6$ & $61.0 / 85.4$ & 0.015 \\
\hline Day 30 & $40.7 / 9.1$ & $59.3 / 90.9$ & 0.003 \\
\hline Day 90 & $42.8 / 16.4$ & $57.2 / 83.6$ & 0.008 \\
\hline \multicolumn{4}{|l|}{ lymphocyte blood count $(\mathrm{G} / \mathrm{L})<0.8 / \geq 0.8(\%)$} \\
\hline Day 0 & $0.0 / 25.3$ & 100.0/74.7 & 1.000 \\
\hline Day 30 & $42.9 / 21.0$ & $57.1 / 79.0$ & 0.090 \\
\hline Day 90 & $53.8 / 20.0$ & $46.2 / 80.0$ & 0.015 \\
\hline \multicolumn{4}{|l|}{ gammaglobulin blood concentration (g/dL) < 0.8/ $\geq 0.8$ (\%) } \\
\hline Day 0 & $18.2 / 24.8$ & $81.8 / 75.2$ & 0.623 \\
\hline Day 90 & $41.7 / 5.9$ & $58.3 / 94.1$ & 0.0004 \\
\hline
\end{tabular}

in 51 recipients $(76 \%)$ compared with seven recipients (37\%) in the CMV R-group ( $p=0.001)$. We assessed the value of the QuantiFERON-CMV assay for predicting protection against $\mathrm{CMV}$ infection at three time-points. At each time-point, patients with positive QuantiFERON-CMV had a significantly lower subsequent incidence of CMV infection than patients with a nonreactive assay (Table 3 ).

Cytomegalovirus infection occurred in 15 of $67 \mathrm{R}+$ recipients (22\%) and six of $19 \mathrm{R}$ - recipients (32\%), indicating that the proportion of patients with CMV infection was 
comparable between groups, regardless of serological status $(\mathrm{OR}=1.6,95 \%$ confidence interval $[\mathrm{Cl}]=0.51-4.92$, $p=0.410)$ at the time of transplantation. Only nine of 58 recipients $(16 \%)$ with cell-mediated immunity developed CMV infection compared with 12 of 28 recipients (43\%) with a nonreactive QuantiFERON assay $(p=0.005)$. As shown in Fig. 2, stratified analysis using the MantelHaenszel method revealed no significant differences in the incidence of CMV infection stratified according to QuantiFERON-CMV assay results with regard to the recipient's pretransplant CMV IgG serology (OR $=1.09$ for CMV IgG(+) group vs. CMV IgG(-) group $95 \% \mathrm{Cl}=0.31-$ $3.84, p=0.985)$. The incidence of CMV infection was significantly higher in the QuantiFERON-CMV-negative group during follow-up (Fig. 3). A Kaplan Meier curve of the time to CMV infection in recipients who were QuantiFERON-CMV-positive vs. those who were QuantiFERON-negative is shown in Fig. 3.

Hypogammaglobulinemia and lymphocytpenia - relationship with postprophylaxis CMV infection Cytomegalovirus infection occurred in 15 of 36 patients (42\%) with HGG on day 90 posttransplantation compared with two of 34 patients $(6 \%)$ without HGG $(p=0.0004)$. Cytomegalovirus infection occurred in seven of 13 patients (54\%) with lymphocytopenia compared with 14 of 70 patients $(20 \%)$ who were nonlymphocytopenic $(p=0.015)$.

The multivariate analysis included all parameters that were analyzed in the univariate analyses. The maximum model to be considered was identified. The optimal subset of variables was then selected, and their reliability was assessed. The factors that were found to be independent risk factors for postprophylaxis CMV infection were HGG on day 90 posttransplantation, a nonreactive QuantiFERON-CMV assay, and lymphocytopenia on day 90 posttransplantation (Table 4). Hypogammaglobulinemia and a nonreactive QuantiFERON-CMV assay had the strongest predictive value for the incidence of postprophylaxis CMV infection.

\section{Discussion}

To date, QuantiFERON-CMV has not been well studied with regard to the risk of postprophylaxis CMV infection in kidney transplant recipients who are subjected to such a preventive modality, regardless of pretransplant serological status.

In our study, all of the patients (except one) were either $\mathrm{R}+$ or received the kidney from a seropositive donor $\mathrm{D}(+)$, which made them at-risk for CMV infection after transplantation. In our study, all of the patients (except one) were either $\mathrm{R}(+)$ or received a kidney from a seropositive donor $(D[+])$, which made them at-risk for CMV infection after transplantation. In the $\mathrm{R}(-)$ group, all of the patients who developed CMV infection and
CMV disease received the kidney from $\mathrm{D}(+)$. This tends to confirm the fact that the CMV sero-status of both recipients and donors' is a very important predictor of post-transplant CMV infection and CMV disease.

However, a major finding of the present study was that a negative QuantiFERON-CMV result better defines the risk of postprophylaxis CMV infection than pretransplant CMV serostatus. Furthermore, negative QuantiFERONCMV results appear to be even more predictive of the individual risk for CMV infection. Our results are consistent with the report of Kumar et al. [15]. These authors evaluated the predictive value of the QuantiFERON assay for determining whether patients who complete a course of therapy for CMV DNAemia require secondary antiviral prophylaxis. At the end of treatment, $48 \%$ of the recipients had a negative QuantiFERON-CMV. The recurrence of CMV infection was observed in 69\% of QuantiFERONCMV-negative recipients, despite more prolonged antivirals, in contrast to $7 \%$ of recipients who had a positive QuantiFERON-CMV $(p=0.001)$.

An increasing number of studies have been conducted to investigate the feasibility of immune monitoring of the CMV-specific T-cell response as a clinical marker for predicting CMV infection posttransplantation. Sester et al. analyzed CMV-specific T-cell levels in 96 solid organ transplant recipients. They reported a strong correlation between low absolute numbers of CMV-specific CD4 T cells and the frequency of infectious episodes in lung but not kidney transplant recipients [16]. Eid et al. analyzed IFN- $\gamma$-producing CMV-specific CD4+ and CD8 $+\mathrm{T}$ cells at serial time-points among 44 high- and intermediate-risk kidney transplant recipients who received 3 months of valganciclovir prophylaxis. The study found no significant association between CMV-specific $\mathrm{T}$ cells and the time to CMV DNAemia, but the conclusions were limited by the small number of patients who experienced CMV DNAemia [17]. Nonetheless, the relatively homogeneous reports of kidney transplant recipients suggest a strong correlation between detection of the CMV-specific effector T-cell response and the risk of posttransplantation CMV infection [18-28].

The present study found that $24 \%$ of the recipients had no detectable cellular immunity to CMV in the QuantiFERON-CMV assay, despite positive pretransplant serology. This is consistent with other studies that showed that $23-50 \%$ of anti-CMV IgG pretransplant seropositive recipients had no functional T-cell response to CMV [18, 29]. In another study, $12 \%$ of healthy IgG-seropositive subjects had undetectable cellular immunity, based on both the QuantiFERON-CMV and Enzyme-Linked ImmunoSpot tests, suggesting the inability of certain individuals to recognize the pp65 (ppUL83) stimulus peptide or the presence of the atypical or uncommon HLA haplotypes of these subjects [30]. The high proportion of patients with 


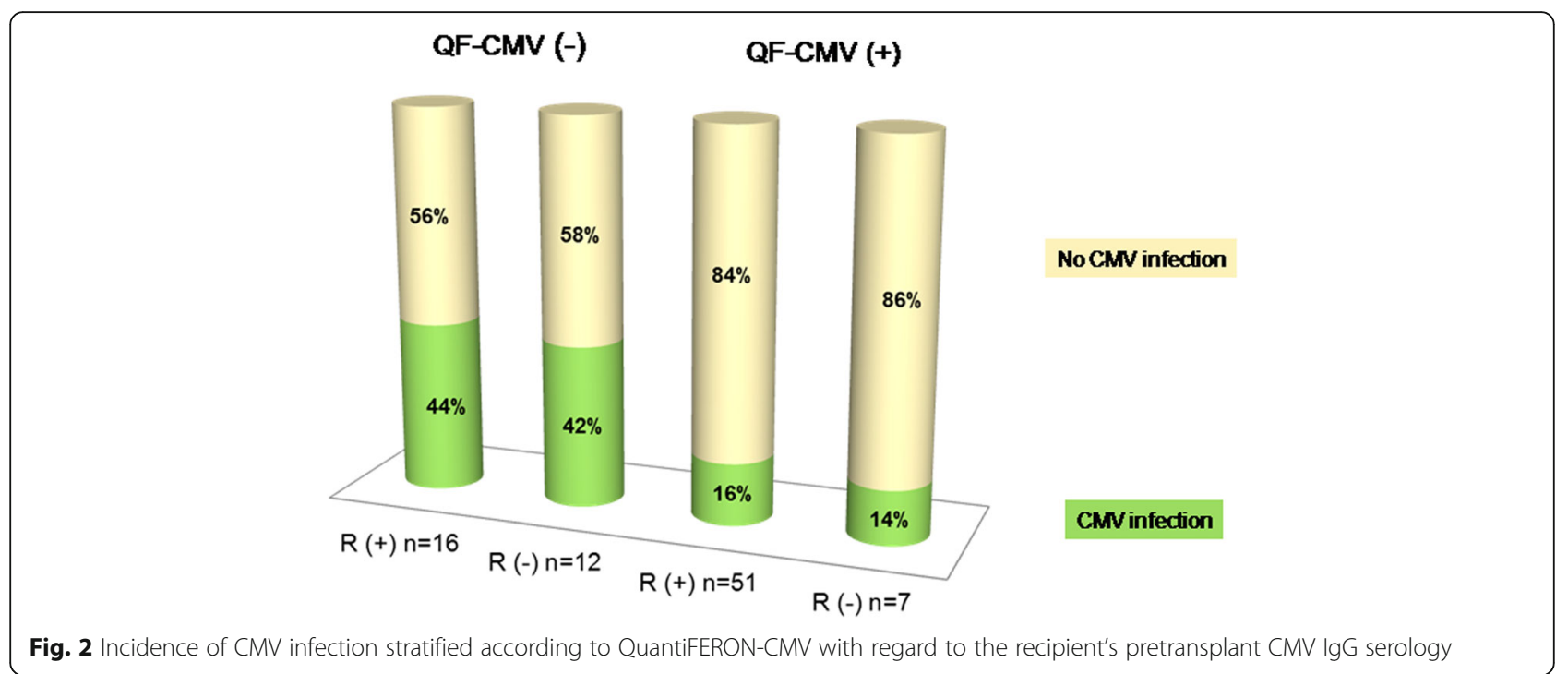

discordance between CMV cellular immunity and the humoral response may also be potentially caused by high susceptibility of the mitogen-dependent response to the action of immunosuppressive drugs, such as tacrolimus and mycophenolate mofetil.

Up to $37 \%$ of recipients who were anti-CMV IgG seronegative at the time of transplantation had a positive QuantiFERON-CMV result. This was not caused by false negatives of the CMV serology test because the repetition of CMV serology 90 days posttransplantation confirmed the negative serostatus of these recipients for IgG. The discrepancy between the results of QuantiFERON-CMV and CMV IgG serology in patients before and after kidney transplantation has been reported by others. The positive agreement (73\%) between the QuantiFERON-CMV results and CMV serology in hemodialysis patients is less than the positive agreement of $88-97 \%$ that was previously reported in healthy adults [19]. In the same study, 13\% of the QuantiFERON-CMV measurements revealed positive test results in seronegative dialysis patients, and $21 \%$ of $\mathrm{CMV}$-seronegative hemodialysis patients had positive T-Track CMV results. In kidney transplant recipients, the frequency of detecting CMV-reactive effector $\mathrm{T}$ cells in CMV-seronegative transplant recipients has been reported to be up to $30 \%$ [20]. One possible explanation is that these recipients might have been appropriately sensitized before transplantation, despite the absence of CMV IgG in their serum. Alternatively, primary CMV-specific effector Tcell responses recover quickly and effectively immediately after transplantation, thus providing sufficient protection and control of CMV replication [20]. Further investigations are needed to address these possibilities in kidney transplant candidates. Notably, analyses that are

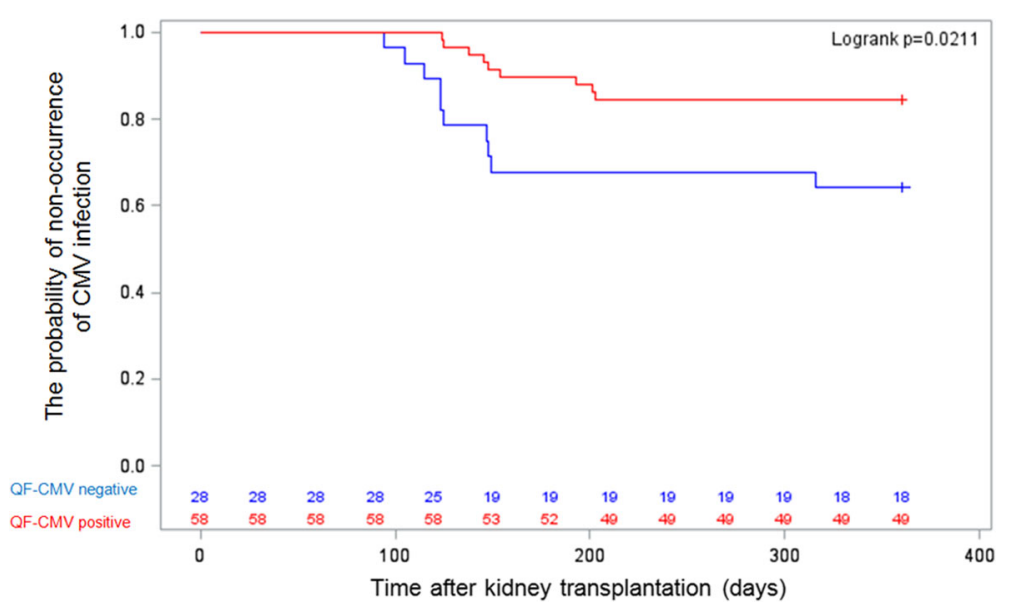

Fig. 3 Time to development of CMV infection in patients with a positive (red line) vs. negative (blue line) QuantiFERON-CMV assay result. QF-CMV negative, QF-CMV positive 
Table 4 The best subset of variables with the strongest predictive value for the incidence of posttransplant CMV infection according to the multivariate analysis

\begin{tabular}{llll}
\hline The best subset of parameters & \multicolumn{4}{c}{ Multivariate analysis } \\
\cline { 2 - 5 } & OR & $95 \% \mathrm{Cl}$ & $\mathrm{P}$ \\
\hline HGG on day 90 posttransplantation & 7.6 & $1.7-34.1$ & 0.008 \\
Nonreactive QuantiFERON-CMV assay & 4.2 & $1.1-15.6$ & 0.033 \\
Lymphocytopenia on day 90 posttransplantation & 3.5 & $0.6-19.2$ & 0.146 \\
\hline
\end{tabular}

limited to the serological measurement of specific antibodies may not provide a sufficient assessment of the absolute memory repertoire because it excludes preformed CMV-specific memory B cells that can exist in the absence of detectable circulating anti-CMV IgG antibodies [31,32].

One possible limitation of the present study was that we did not include three cases of indeterminate QuantiFERON-CMV results. The possible inclusion of patients with indeterminate results has been controversial. According to the manufacturer, indeterminate results are not interpretable. For the purposes of analysis, Manuel et al. classified negative and indeterminate results together as nonreactive [33]. Notably, $37 \%$ of the organ transplant recipients in their study were treated with thymoglobulin, which is known to increase the rate of lymphocytopenia and the rate of indeterminate QuantiFERON-CMV results. In the aforementioned study, patients with indeterminate results had the highest risk of developing CMV disease, prompting the authors to suggest that indeterminate results reflect a high net state of immunosuppression. However, this possibility was not supported by other investigators who did not confirm the predictive value of indeterminate results for determining the risk of $\mathrm{CMV}$ infection [34]. In the present study, the number of patients with indeterminate results was too small to allow assessment of their risk for posttransplantation CMV infection.

In previous studies, the risk of CMV infection in organ transplant recipients was associated with maintenance immunosuppression and the usage of T-cell-depleting antibodies $[7,8]$. We did not observe a correlation between maintenance immunosuppression and the occurrence of CMV infection. A possible explanation for this fact is that the majority (98\%) of the patients in the present study received the same protocol (i.e., combination of tacrolimus, steroids, and mycophenolate mofetil or mycophenolate sodium as maintenance immunosuppression). Similar to previous reports, the present study confirmed that induction therapy is a risk factor for postprophylaxis CMV infection, but such a conclusion is limited by the small number of patients who present Tcell depletion [35].

Hypogammaglobulinemia is defined as a low level of any or all of the five classes of immunoglobulins.
Although the precise mechanism of the evolution of HGG posttransplantation is unclear, secondary HGG has been found to correlate with various factors, including treatment with glucocorticosteroids and mycophenolate mofetil [36]. Other data suggest that HGG develops more frequently after kidney transplantation in patients who are being treated with mycophenolate mofetil compared with patients who are being treated with azathioprine [37]. One of the most interesting findings of the present study was that at the time of prophylaxis discontinuation, HGG was the strongest predictor of CMV infection. Corales et al. reported the occurrence of CMV infection in five of six heart transplant recipients with severe, profound HGG. Lymphocyte subset analysis suggested a decrease in the number of $\mathrm{CD} 4+\mathrm{T}$ cells, which are required to stimulate B-cell responses [38]. Surprisingly, very sparse information is available on the association between HGG and viral infections following kidney transplantation. Broeders et al. reported that combined HGG (IgG and IgA or IgG and IgM) was associated with more frequent infectious complications, including CMV infection. Similar to our findings, isolated hypo-IgG, although frequent, has not been identified as a predisposing factor for CMV infection after kidney transplantation $[39,40]$.

\section{Conclusions}

Despite the relatively small sample size in the present study, the findings have relevant clinical implications. Current clinical protocols use very few predictors of the occurrence of postprophylaxis CMV infection. The present results indicate that negative QuantiFERON-CMV results in recipients who receive antiviral prophylaxis is a strong predictor of the risk of postprophylaxis CMV infection, independent of pretransplant CMV serology.

We also found that induction therapy, lymphocytopenia, and HGG on day 90 posttransplantation were risk factors for postprophylaxis CMV infection.

The negative QuantiFERON-CMV assay results suggest an inadequate cellular response and may be used as an indication for extending antiviral prophylaxis or monitoring CMV DNAemia after prophylaxis withdrawal.

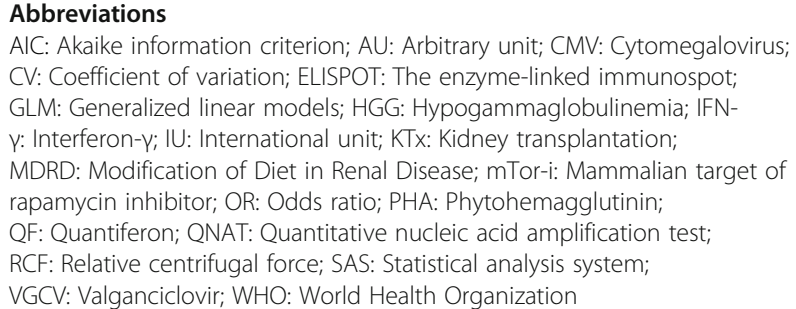




\section{Funding}

The study was financially supported by statutory fund granted by Medical University of Warsaw.

\section{Availability of data and materials}

The datasets used/and or analyzed in this study are available from the corresponding authors on reasonable request.

\section{Authors' contributions}

D.D-M participated in: research design, performance of the research, analysis, interpretation of data, drafting the work, writing of the paper. APP participated in: research design, revising the work critically, writing of the paper. AS, MSŚ, AJ and ES participated in the performance of the research, reviewed all the medical records and collected CMV data. AS and ES together evaluated CMV data to obtain the diagnosis of CMV infection and CD8+ T-cell-mediated immunity. PD, AJ, MC, JG and D.M-S collected completing data and blood samples and assisted in collection of the other clinical data. MD, JG, APP, MC and AK reviewed and made improvements in the manuscript. The final manuscript was read and approved by all authors.

\section{Ethics approval and consent to participate}

The study was approved by the Ethical Committee of Medical University of Warsaw and complied with the provisions of the Good Clinical Practice Guidelines and the Declaration of Helsinki. All patients provided written informed consent prior to participation.

\section{Competing interests}

The authors declare that they have no competing interests.

\section{Publisher's Note}

Springer Nature remains neutral with regard to jurisdictional claims in published maps and institutional affiliations.

\section{Author details}

'Department of Transplantation Medicine, Nephrology, Internal Diseases, T. Orłowski Institute of Transplantation Medical University of Warsaw, 59 Nowogrodzka Street, 02-006 Warsaw, Poland. '2Department of Immunology, Transplantology, Internal Diseases, T. Orłowski Institute of Transplantation Medical University of Warsaw, 59 Nowogrodzka Street, 02-006 Warsaw, Poland. ${ }^{3}$ Department of General and Transplant Surgery, T. Orłowski Institute of Transplantation Medical University of Warsaw, 59 Nowogrodzka Street, 02-006 Warsaw, Poland.

Received: 3 August 2017 Accepted: 3 April 2018

Published online: 16 April 2018

\section{References}

1. Fishman JA. Infection in solid-organ transplant recipients. N Engl J Med. 2007:357:2601-14

2. Paya C, Humar A, Dominguez E, Washburn K, Blumberg E, Alexander B, et al. Valganciclovir Solid Organ Transplant Study Group. Efficacy and safety of valganciclovir vs. oral ganciclovir for prevention of cytomegalovirus disease in solid organ transplant recipients. Am J Transplant. 2004:4:611-20.

3. Khoury JA, Storch GA, Bohl DL, Schussler RM, Torrence SM, Lockwood M, et al. Prophylactic versus preemptive oral valganciclovir for the management of cytomegalovirus infection in adult renal transplant recipients. Am J Transplant. 2006;6:2134-43.

4. Humar A, Lebranchu Y, Vincenti F, Blumberg EA, Punch JD, Limaye AP, et al. The efficacy and safety of 200 days valganciclovir cytomegalovirus prophylaxis in high-risk kidney transplant recipients. Am J Transplant. 2010; 10(5):1228-37.

5. Limaye AP, Bakthavatsalam R, Kim HW, Randolph SE, Halldorson JB, Healey $P J$, et al. Impact of cytomegalovirus in organ transplant recipients in the era of antiviral prophylaxis. Transplantation. 2006;81:1645-52.

6. Couzi L, Helou S, Bachelet T, Moreau K, Martin S, Morel D, et al. High incidence of anticytomegalovirus drug resistance among D+R- kidney transplant recipients receiving preemptive therapy. Am J Transplant. 2012; 12(1):202-9.

7. Humar A, Snydman D. Cytomegalovirus in solid organ transplant recipients. Am J Transplant. 2009;9(suppl 4):S78-86.
8. Kotton CN, Kumar D, Caliendo AM, Asberg A, Chou S, Danziger-Isakov L, et al. Updated international consensus guidelines on the management of cytomegalovirus in solid-organ transplantation. Transplantation. 2013;96(4): 333-60.

9. Torre-Cisneros J, Aguado JM, Caston JJ, Almenar L, Alonso A, Cantisan S, et al. Management of cytomegalovirus infection in solid organ transplant recipients: SET/GESITRA-SEIMC/REIPI recommendations. Transplant Rev. 2016;30(3):119-43.

10. Westall GP, Mifsud NA, Kotsimbos T. Linking CMV serostatus to episodes of CMV reactivation following lung transplantation by measuring CMV-specific CD8+ T-cell immunity. Am J Transplant. 2008;8(8):1749-54.

11. Carbone J, Lanio N, Gallego A, et al. Simultaneous monitoring of cytomegalovirus-specific antibody and T-cell levels in seropositive heart transplant recipients. J Clin Immunol. 2012;32(4):809-19.

12. Emery VC, Asher $K$, de Juan Sanhuan C. Importance of the cytomegalovirus seropositive recipient as a contributor to disease burden after solid organ transplantation. J Clin Virol. 2012;54(2):125-9.

13. Mattes FM, Hainsworth EG, Geretti AM, Nebbia G, Prentice G, Potter M, et al. A randomized, controlled trial comparing ganciclovir to ganciclovir plus foscarnet (each at half dose) for preemptive therapy of cytomegalovirus infection in transplant recipients. J Infect Dis. 2004;189: 1355-61.

14. Walker S, Fazou C, Crough T, Holdsworth R, Kiely P, Veale M, et al. Ex vivo monitoring of human cytomegalovirus-specific CD8+ T-cell responses using QuantiFERONCMV. Transpl Infect Dis. 2007;9:165-70.

15. Kumar D, Mian M, Singer L, Humar A. An interventional study using cellmediated immunity to personalize therapy for cytomegalovirus infection after transplantation. Am J Transplant. 2017;17(9):2468-73. https://doi.org/10. 1111/ajt.14347.

16. Sester U, Gartner BC, Wilkens H, Schwaab B, Wossner R, Kindermann I, et al. Differences in CMV-specific T-cell levels and long-term susceptibility to CMV infection after kidney, heart and lung transplantation. Am J Transplant. 2005;5: 1483-9.

17. Eid AJ, Brown RA, Arthurs SK, Lahr BD, Eckel-Passow JE, Larson TS, et al. A prospective longitudinal analysis of cytomegalovirus (CMV)-specific CD4+ and CD8+ T cells in kidney allograft recipients at risk of CMV infection. Transplant Int. 2010;23:506-13.

18. Lopez-Oliva MO, Martinez V, Buitrago A, Jimenez C, Rivas B, Escuin F, et al. Pretransplant CD8 T cell response to IE-1 discriminates seropositive kidney recipients CD8+ T cell response in CMV-seropositive candidates at risk of developing CMV infection posttransplant. Transplantation. 2014;97:839-45.

19. Banas B, Böger CA, Lückhoff G, Krüger B, Barabas S, Batzilla J, et al. Validation of T-track ${ }^{\circledR}$ CMV to assess the functionality of cytomegalovirus-reactive cellmediatedimmunity in hemodialysis patients. BMC Immunol. 2017;18(1):15. https://doi.org/10.1186/s12865-017-0194-Z.

20. Lucia M, Crespo E, Melilli E, Cruzado JM, Luque S, Llaudo I, et al. Preformed frequencies of cytomegalovirus (CMV)-specific memory $T$ and B cells identify protected CMV-sensitized individuals among seronegative kidney transplant recipients. Clin Infect Dis. 2014;59(11):1537-45.

21. Radha R, Jordan S, Puliyanda D, Bunnapradist S, Petrosyan A, Amet N, et al. Cellular immune responses to cytomegalovirus in renal transplant recipients. Am J Transplant. 2005;5:110-7.

22. Egli A, Binet I, Binggeli S, Jäger C, Dumoulin A, Schaub S, et al. Cytomegalovirus-specific T-cell responses and viral replication in kidney transplant recipients. J Transl Med. 2008;6:29.

23. Abate D, Saldan A, Fiscon M, Cofano S, Paciolla A, Furian L, et al. Evaluation of cytomegalovirus (CMV)-specific T cell immune reconstitution revealed that baseline antiviral immunity, prophylaxis, or preemptive therapy but not antithymocyte globulin treatment contribute to CMV-specific T cell reconstitution in kidney transplant recipients. J Infect Dis. 2010;202:585-94.

24. Sund F, Lidehall AK, Claesson K, Foss A, Totterman TH, Korsgren O, et al. CMV-specific T-cell immunity, viral load, and clinical outcome in seropositive renal transplant recipients: a pilot study. Clin Transpl. 2010;24:401-9.

25. Gerna G, Lilleri D, Chiesa A, Zelini P, Furione M, Comolli G, et al. Virologic and immunologic monitoring of cytomegalovirus to guide preemptive therapy in solid-organ transplantation. Am J Transplant. 2011;11:2463-71.

26. Lisboa LF, Kumar D, Wilson LE, Humar A. Clinical utility of cytomegalovirus cell-mediated immunity in transplant recipients with cytomegalovirus viremia. Transplantation. 2012;93:195-200.

27. Bestard O, Lucia M, Crespo E, van Liempt B, Palacio D, Melilli E, et al. Pretransplant immediately early-1-specific $T$ cell responses provide 
protection for CMV infection after kidney transplantation. Am J Transplant. 2013;13:1793-805.

28. Shabir S, Kaul B, Pachnio A, Bancham GD, Smith H, Chand S, et al. Impaired direct priming of CD8 T cells by donor-derived cytomegalovirus following kidney transplantation. J Am Soc Nephrol. 2013;24:1698-708.

29. Cantisan S, Rodelo-Haad C, Paez-Vega A, Nieto A, Vaquero JM, Poyato A, et al. Factors related to the development of CMV-specific CD81T cell response in CMV-seropositive solid organ transplant candidates. Am J Transplant. 2015;15:715-22

30. Abate D, Saldan A, Mengoli C, Fiscon M, Silvestre C, Fallico L, et al. Comparison of Cytomegalovirus (CMV) enzyme-linked immunosorbent spot and CMV Qantiferon gamma interferon-releasing assays in assessing risk of CMV infection in kidney transplant recipients. J Clin Microbiol. 2013;51(8):2501-7.

31. Kumar D, Chernenko S, Moussa G, Cobos I, Manuel O, Preiksaitis J, et al. Cellmediated immunity to predict cytomegalovirus disease in high-risk solid organ transplant recipients. Am J Transplant. 2009;9(5):1214-22.

32. Bauer $T$, Jilg W. Hepatitis $B$ surface antigen-specific $T$ and $B$ cell memory in individuals who had lost protective antibodies after hepatitis $B$ vaccination Vaccine. 2006;24:572-7.

33. Manuel O, Husain S, Kumar D, Zayas C, Mawhorter S, Levi ME, et al. Assessment of cytomegalovirusspecific cell-mediated immunity for the prediction of cytomegalovirus disease in high-risk solid-organ transplant recipients: a multicenter cohort study. Clin Infect Dis. 2013;56:817-24.

34. Sood S, Haifer C, Yu L, Pavlovic J, Gow PJ, Jones RM, et al. Targeted individual prophylaxis offers superior risk stratification for cytomegalovirus reactivation after liver transplantation. Liver Transpl. 2015;21(12):1478-85.

35. Lebranchu Y, Bridoux F, Buchler M, Le Meur Y, Etienne I, Toupance O, et al. Immunoprophylaxis with basiliximab compared with antithymocyte globulin in renal transplant patients receiving MMF-containing triple therapy. Am J Transplant. 2002;2:48-56.

36. Mawhorter S, Yamani MH. Hypogammaglobulinemia and infection risk in solid organ transplant recipients. Curr Opin Organ Transplant. 2008;13(6):581-5.

37. Keven K, Sahin M, Kutlay S, Sengul S, Erturk S, Ersoz S, et al. Immunoglobulin deficiency in kidney allograft recipients: comparative effects of mycophenolate mofetil and azathioprine. Transpl Infect Dis. 2003;5:181.

38. Corales R, Chua J, Mawhorter SD, Young JB, Starling R, Tomford JW, et al. Significant hypogammaglobulinemia in six heart transplant recipients: an emerging clinical phenomenon? Transplant Infect Dis. 2000;2:133-9.

39. Broeders EN, Wissing KM, Hazzan M, Ghisdal L, Hoang AD, Noel C, et al. Evolution of immunoglobulin and mannose binding protein levels after renal transplantation: association with infectious complications. Transpl Int. 2008;21:57-64.

40. Fernández-Ruiz M, López-Medrano F, Varela-Peña P, Lora-Pablos D, GarcíaReyne A, González E, et al. Monitoring of immunoglobulin levels identifies kidney transplant recipients at high risk of infection. Am J Transplant. 2012; 12(10):2763-73.

\section{Ready to submit your research? Choose BMC and benefit from:}

- fast, convenient online submission

- thorough peer review by experienced researchers in your field

- rapid publication on acceptance

- support for research data, including large and complex data types

- gold Open Access which fosters wider collaboration and increased citations - maximum visibility for your research: over $100 \mathrm{M}$ website views per year

At BMC, research is always in progress.

Learn more biomedcentral.com/submissions 